\title{
Drugs of Abuse and Addiction - Overview and Current Status
}

\section{Khanh ND*}

Faculty of Food, Environment and Nurse, Dong Nai Technology University, Vietnam

*Corresponding author: Khanh ND, Faculty of Food, Environment and Nurse, Dong Nai Technology University, Nguyen Khuyen Street, Trang Dai Ward, Bien Hoa City, Dong Nai, Vietnam, Tel: 0084913650604, E-mail: nguyendikhanh@dntu.edu.vn

Citation: Khanh ND (2018) Drugs of Abuse and Addiction - Overview and Current Status. J Neurol Neurol Disord 4(1): 106

Received Date: April 25, 2018 Accepted Date: May 29, 2018 Published Date: June 02, 2018

\begin{abstract}
Today, both nonprescription and prescription drugs used by people for disease treatment, illicit or reward purposes have diverse effects on health permanently or long-lastingly. The effects may even continue and lead to the death or disabilities in child when a person is no longer use the substance. Substances that cause addiction trigger intense feeling of euphoria then lead to loss of control of selfbehavior and perception. Problem regarding to drug abuse, tobacco and alcohol has always been a hot issue in every country around the world. Apart from alcohol use, drug abuse and addiction cause high risk of accidents, injuries and social violence incidences. It affects to the brain, behaviors, birth defects, drug dependences. Our responsibility nowadays is to help reduce the burden of addiction in a proportion of the world's population. There have been many reports on drug of abuse and neuropsychopharmacology such as Parkinson and other related consequences and diseases. This review paper focuses on the effects of drug abuse and addiction, both Central Nervous System (CNS) stimulants and depressants.
\end{abstract}

Keywords: Drug abuse; Drug addiction; Drug dependence; CNS stimulants; CNS depressants; Cannabis; Cocaine, Amphetamines; Caffeine; Nicotine

\section{Introduction}

"Drug of abuse" can be described as a patterned and inappropriate use of a drug for a non-medical intention [1]. It has different definitions in different contexts such as public health, medical and criminal justice. In some circumstances, when individuals are under the influence of substance with long time, they might change their personality since then leading to criminal or anti-social behaviors [2]. The ways they take drug or substance and continue to use are harmful not only to themselves but also to others in community, which might form substance-related disorder. Many variables that do not directly related to a drug can cause whether an individual becomes a drug addict. Cocaine is a substance very easy to be abused as its pharmacologic characteristics have been studied by many researchers. Interestingly, nicotine substance also poses that high possibility of abuse to user but twice than cocaine. Apart from pharmacologic abuse characteristics of cocaine and nicotine, there are also other psychosocial factors that contribute to the onset and continuation of drug abuse and misuse. In fact, many studies have been studied on drug abuse in term of pharmacologic aspects rather than the correlation between drug users and their environment [3].

Substances that cause addiction trigger intense feeling of euphoria then lead to loss of control of self-behavior and perception. A wide variety of distinct types of drugs and other chemical substances are exposed to addiction [5]. Bodybuilders and some athletes normally get addicted anabolic steroids to enhance athletic performance and add to their muscle mass. The most commonly abused groups of drugs are those that act on the CNS to cause intense feelings of euphoria or alter perception $[1,6]$.

Our responsibility nowadays is to help reduce the burden of addiction in a proportion of the world's population. Hence, Worldwide Health Organization (WHO) is facilitating countries in organizing, developing, monitoring and evaluating of treatment and other substance-abuse-related services. The latest statistic from WHO in 2017 showed that each year there are 3.3 million individuals abusing alcohol, 38\% of population drink alcohol with 17 liters of alcohol consumption each year; about 15.3 million people abusing drugs. They also reported that over 148 countries with injecting drug use, 120 out of those got HIV infection and other infectious diseases [7].

Problem regarding to drug abuse, tobacco and alcohol has always been a hot issue in every country around the world. According to the survey results, named National Survey of Drug Use and Health (NSDUH), chaperoned by Substance Abuse and Mental Health Services Administration (SAMHSA) in 2014 in USA and published in 2015, approximately 10.1\% of USA population correspond 
to 27.1 million people in this country used addicted substances within 30 days of the survey period. Drug abuse, infectious disease and mental health issue force under millions of pre-adulthood and adults in the United State (US) and they lead to burden of disease for society [7-9]. NSDUH, which is an annual conducted survey in the US, supports statistical information on substance use disorder (SUDs), alcohol use, illicit drug consumption and mental health issues. This source of information helps SAMHSA and other policy-makers to appraise and improve national healthcare progress. Specifically, it provides data across time to gauge trends in drug abuse and healthcare issues, and from that the information need to be balanced with periodic to revise the NSDUH report content to highlight changes in society and emerging issues. Each year, there may be a minor change can be added to the NSDUH report and the NSDUH 2015, the latest one involved a wide array of changes in trends with different estimates. In 2015, they conducted a survey with indicators of substance misuse and mental-health-related in group of people ranging from 12 or older. There were 27.1 million people abused to illicit drugs, 22.2 million abused to marijuana, 52.0 million smoke cigarettes and 138.3 million alcohol drinkers [9]. The result encouraged changes from researchers and policy-makers for drug abuse and mental health issues. The statistics showed that trends are being kept presenting for estimates which are supposed to have remained as compared to ones in earlier years. For instance, the percentage of individuals addicted to marijuana and heroin since 2002 to 2015 remain relatively, and mental health issues related to drug abuse also persisted comparatively unchanged since 2008 to 2015 . Among the list of drugs of abuse, marijuana had the highest rate of abuse 22.2 million people are abusing it and then follow by nonmedical use of prescription pain medication with estimated 4.3 million people. Adding up to the list, there are 17.0, 1.9, 1.5 and 0.4 million people are abusing alcohol, tranquilizers, cocaine and heroin, respectively. Substance abuse alone costs about $\$ 700$ billion to pay for those health care costs in America annually [8].

In the United States, drug overdose is the top cause of injury mortality. To be more specific, the death rate due to drug overdose in this country was increased steadily from 6.0 percent in 1999 to 13.8 percent in 2013 (the ratio indicated in over 1000,000 population of the country) [4]. In this period, the increase in drug overdose is mainly consequence of abuse and misuse of prescription drugs such as stimulants, tranquilizers/sedatives and especially opioid analgesics. Those are prescribed extensively but substantially varied from state to state in the US. In fact, users take drug without medical use purpose or they get drugs by obtaining various prescriptions from different prescribers. It leads to serious and gradually burdened drug of abuse issue to the society. A study by Paulozzi and his colleges in 2013 indicated that a daily dose of more than 100 morphine milligram equivalents (MMEs) per day together with the use of multiple prescribers could lead to high risks of drug overdose [10]. Ordinarily, list of abused drugs in the US include marijuana, opioids, cocaine (including crack), amphetamine, methamphetamine, phencyclidine and benzodiazepines. Moreover, users are also easily getting abused by various designer drugs such as spices (synthetic cannabinoids), salts (synthetic cathinone), MDMA, ketamine, Rohypnol, GHB. Recently, abusing of peyote cactus and magic mushrooms is rising with less commonly abused effects and consequences than those mentioned above [11]. Commonly abused drugs in United States are listed in Table 1.1 and Street names of commonly abused drugs are listed in Table 1.2

\begin{tabular}{|c|c|c|}
\hline Class of drug & Commonly abused & Less commonly abused \\
\hline Stimulants & $\begin{array}{c}\text { Amphetamine, methamphetamine, 3,4-methylenedi- } \\
\text { oxymethamphetamine } \\
\text { (MDMA), 3,4-Methylenedioxyamphetamine (MDA), } \\
\text { synthetic } \\
\text { cathinone, cocaine }\end{array}$ & $\begin{array}{l}\text { Designer drugs other than } \\
\text { MDMA and MDA which are } \\
\text { related to amphetamine } \\
\text { structure }\end{array}$ \\
\hline Opioids & $\begin{array}{l}\text { Heroin, morphine, codeine, } \\
\text { oxycodone, hydrocodone, } \\
\text { hydromorphone, methadone, } \\
\text { meperidine, propoxyphene }\end{array}$ & $\begin{array}{l}\text { Fentanyl and structurally } \\
\text { related designer drugs }\end{array}$ \\
\hline Cannabinoid & $\begin{array}{l}\text { Marijuana (tetrahydrocannabinol), } \\
\text { Hashish along with synthetic cannabinoids }\end{array}$ & $\begin{array}{l}\text { Abuse of hemp product is rare } \\
\text { None }\end{array}$ \\
\hline Anesthetics & Cannabinoids & None \\
\hline Benzodiazepines & $\begin{array}{c}\text { Phencyclidine, ketamine } \\
\text { Alprazolam, lorazepam, temazepam, }\end{array}$ & \\
\hline Barbiturates & Diazepam, flunitrazepam, etc., & Phenobarbital \\
\hline Hallucinogens & $\begin{array}{c}\text { Pentobarbital, secobarbital } \\
\text { Lysergic acid diethylamide (LSD) }\end{array}$ & $\begin{array}{l}\text { Magic mushroom, peyote } \\
\text { Cactus }\end{array}$ \\
\hline Club drugs & $\begin{array}{l}\text { MDMA, ketamine, gammahydroxybutyric acid } \\
\text { (GHB), Rohypnol (flunitrazepam) }\end{array}$ & \\
\hline $\begin{array}{l}\text { Prescription } \\
\text { Drugs }\end{array}$ & $\begin{array}{l}\text { Oxycodone, hydromorphone, } \\
\text { methadone, propoxyphene, } \\
\text { benzodiazepines, zolpidem, } \\
\text { zaleplon, methylphenidate, } \\
\text { dextro-amphetamine }\end{array}$ & $\begin{array}{l}\text { Hydrocodone, mephobarbital, } \\
\text { phenmetrazine }\end{array}$ \\
\hline
\end{tabular}

Table 1.1: Abused drugs in the United States [4] 


\begin{tabular}{|c|c|}
\hline Drug & Street names \\
\hline Amphetamine & Black Beauties, Crosses, Hearts, Speed, Truck Drivers, Uppers \\
\hline Methamphetamine & Ice, Meth, Speed, Crystal, Fire, Glass, Go Fast, Ice \\
\hline MDMA & Ecstasy, Molly, Adam, Clarity, Lover's Speed, Peace \\
\hline MDA & Eve, Sally, Sass \\
\hline Cocaine & Blow, Bump, C, Candy, Charlie, Coke, Crack, Rock, Snow \\
\hline Heroin & Brown Sugar, Horse, White Horse, Junk, Smack \\
\hline Oxycodone & O.C., Oxycet, Oxy, Hillbilly Heroin \\
\hline Barbiturates & Barbs, Pennies, Red Birds, Reds, Yellow Jackets, Yellows \\
\hline Benzodiazepines & Candy, Downers, Sleeping Pills, Tranks \\
\hline Marijuana & $\begin{array}{c}\text { Bud, dope, Ganja, Grass, Green, Joint, Mary Jane, Pot, Reefer, Smoke, Trees, } \\
\text { Weed, Hashish, Gangster, Hash, }\end{array}$ \\
\hline Phencyclidine (PCP) & Angel Dust, Boat, Hog, Love Boat, Peace Pill \\
\hline Ketamine & Cat Valium, K, Special K, Vitamin K \\
\hline $\begin{array}{l}\text { Gamma-hydroxybutyric } \\
\text { acid (GHB) }\end{array}$ & G, Georgia Home Boy, Bodily Harm, Liquid Ecstasy, Liquid X, Soap \\
\hline Rohypnol & $\begin{array}{c}\text { Date Rape Drug, Forget Pill, Forget-Me Pill, Mexican Valium, R2, Reynolds, Rib, } \\
\text { Roach, Roofies, Rope }\end{array}$ \\
\hline Synthetic cathinone & Bath Salts, Cloud Nine, Ivory Wave, Lunar Wave, Vanilla Sk \\
\hline Synthetic cannabinoids & $\begin{array}{c}\text { K2, Spice, Black Mamba, Bliss, Bombay Blue, Fake Weed, Fire, Genie, Moon } \\
\text { Rocks, Skunk, Smacked }\end{array}$ \\
\hline
\end{tabular}

Table 1.2: Street names of commonly abused drugs [4]

\section{Drugs of Abuse and Addiction-Historical Perspective}

In nature, there are numerous plants contain substance capable of changing mood, producing euphoria and possessing addiction after few times of trial. Ancient people around the world have been discovered and used them traditionally and conventionally without modern techniques for extraction and preservation. They used psychoactive plants for different purposes which may cause alterations in consciousness and/ or pleasurable sensations. Those plants and their natural products such as coca leaves, opium, and hemp flowers have been used since thousands of years ago. Historically, poppy plants were historical recorded and firstly cultivated in Mesopotamia back to 3400 BC. They were originally cultivated in Egypt and then introduced into India and China for expanded cultivation and consumption. Among the substances on the list of medical prescription, the oldest recorded one was the Sumerian clay tablet, which was found in about 2100 BC [4].

Archaeologists have found some traces of antique objects, showing the existence of poppy from ancient times. The scholars in this field believe that the opium poppy is referred to on the tablet. Around 1000 alcohol disorder (AD), opium which has been known to purely relieve pain or used in surgical analgesia for millennia ago, especially in diseases of the eye and in diarrhoea, have been used by Arabian physicians. There were many preparations in form of polypharmacy and they were produced like a panacea for all disease. One example was theriaca, which contained up to 60 drugs including opium. Another one was tinctura opii, which have been used till 2000 in Denmark. Abuse of opium was widespread in China, and later there was a ban regulation of opium cultivation, delivery and consumption in there. In 1839, the bootlegging of opium became a workaday industry that distended to the Opium War between Britain and China, however. In the early 1800s, a scientist named Friedrich Serturner isolated morphine from opium and he also was the founder of alkaloid research. Pure opium, in fact, provided medical use purposes with more safe and standardized effect. Pharmacists synthesized and isolated several morphine-like substances to minimize side effects and addiction potential. With modern technologies, scientists have studied in molecular level and gene tic mechanisms and from that, opioid receptors were characterized using binding assays. Nevertheless, it remains unclear about the complexity of the system in term of interaction with transmitter and several neurons signify the target of non-addictive opiates [12]. Gradually, clinical use of opium have been improving using combination therapy, long-term acting formulation and innovative delivery systems.

Unlike alcohol, the first addictive drugs in the United States were opioids and cocaine. During the 1990s, unregulated opiate use led to a series of patent medicines consisting of opiate derivatives. Consequently, people belong to middle-class group in the US became addicted to opioid for the use of such preparations for long time. However, social attitudes about substance misuse remained loosened until after the Civil War. Using morphine to inject and treat for pain, malaria and dysentery for the soldiers had caused harmful effect because many soldiers have become addicted to morphine. In 1859, alkaloid cocaine was firstly isolated and used widespread and there was a double-quick boost in the use and addict ratio of that drug. In the last decade of the 20th century, addicted to cocaine led the users faced to various disorders and symptoms although oral consumption of cocaine in the form of tonics and/or patent medicines was common. Coca-cola Company has still used cocaine-containing syrup as taste stimulating in the soft-drink products up to 1903 before it was banned by the producers and authorities. In the early 1900s, the development of mass media has made people around the world aware of the dangers of using drugs as well as drug-related crimes against society. 
Among opioid addiction prevalent, morphine still was the major opioid of abuse [4,11]. At that time, federal laws were issued to manage the raising of drug abuse. The law enforcement officials compliant the enactment of the Food and Drug Administration Act in 1906, the Harrison Terror Act in 1914 and the Narcotic Drugs Export and Import Act in 1922 and it led to the banned disappearing of cocaine misuse in the 1930s. The reduced availability of cocaine entry and the increase of costs facilitated to boost amphetamines as a stimulant substance for abuse. The use of heroin as intravenous injection also became popular in 1935 onwards, and it was used commonly in place of morphine. During period of World War I and II, drug of abuse have begun to be broadly paralleled with criminality. And last but not least, marijuana which also called "killer weed", related to various cases of murders executed by people under who using it. Hence, in 1937 US authorities have passed a Tax Act for marijuana to effectively prohibit the production, sale, storage and use of its products [4].

\section{Drugs of Abuse and Addiction-Signs and Symptoms}

Depends on the actual substance, there are various health issues related to drug of abuse such as psychological addiction, physical dependence, suicide, homicides, traffic accidents, violence, deaths, unprotected sexual activity, injuries, morbidity, and other social problems [13]. High suicide rates among alcoholics and other drug users. It is a consequence of long-term addiction of alcohol and those substances causing brain physiological deformities as well as social isolation. In addition, the acute intoxicating effects of the substance can be one of the reasons make alcohol-related suicide rate more prospectively happen. Especially, this rate is high with adolescent aging group of alcohol addicts, about $25 \%$ suicide in adolescents being related to alcohol addiction [14]. In the United States, the rate of alcohol-related suicides rate is about 30\% in total. Moreover, alcohol addiction is believed co-relating with criminality of child abuse, rapes, theft, domestic violence and assaults [15].

Substance misuse, including alcohol and prescription drugs, can cause symptoms similar to mental illness which can happen in both intoxicating state and withdrawal state. In other cases, such as amphetamine and/or cocaine abuse, depression or prolonged psychosis may induce psychiatric disorders persist long after detoxification [16]. Addicting symptoms may persist for months after cessation of misuse, it needs protracted withdrawal syndrome. Especially in the case of benzodiazepines, the symptoms from prolonged withdrawal effects may persist for years after cession of addiction. In the case of hallucinogens misuse, the users will be in delusional and other psychotic phenomena long after stopping of use. In another case of abusing of cannabis, it may cause panic outbreaks throughout intoxication and if the user keeps using them, they will be in dysthymia state [14]. Moreover, the scientists have discovered that daily use of cannabis and the use of high-frequently cannabis are individualistically accompany with a higher rate of schizophrenia and other mental illnesses [15]. Sustained alcohol abuse commonly induces severe depression and anxiety, in which the users need prolonged abstinence to get gradual, abates. Even those effects also occur in users even when they are with sustained moderate alcohol. Generally, these substances triggered psychiatric syndromes fade away with prolonged abstinence $[4,14]$.

Impulsivity is categorized by activities founded on whims, sudden desires, or dispositions rather than vigilant thinking [16]. Addicts have higher level to impulsivity and users who consume various substances are inclinable more impulsive [17,18]. Some previous studies, using the Iowa gambling task as a measure, have been conducted with testing group of drug-using individuals compared to healthy control group and the results indicated that the first one is more impulsive rather than the seconds one [19]. Drug-induced changes happened in the frontal cortex, which cause impaired inhibitory and may trigger the loss of impulse control. Adolescences are group of people with high addicted rate due to their hormonal and neurodevelopmental changes which modulate impulse control and very easy to get trials with substances [20]. In general, impulsivity prospectively related to drug of abuse since it is a facet trait in the neuroticism characteristics realm [18]. So far, some different screening tools and assessment methods have been used in adolescence and in adults such as the CRAFFT Screening Test and the CAGE questionnaire, respectively [4].

\section{CNS Stimulants of Abuse}

Stimulants also known as psychostimulants are widely abused in over the world. Those drugs increase activity of the body, have sympathomimetic effects and make users up feelings of invigorating and pleasuring. They include amphetamine, caffeine, ephedrine, methamphetamine, nicotine, cocaine, Catha edulis (Khat), MDMA, Methylenedioxypyrovalerone (MDPV), mephedrone, propylhexedrine and pseudoephedrine [4]. Stimulants have been commonly used as both non-prescriptions and prescription medicines as recreational or performance-enhancing drugs that cause abuse and effects not only on CNS but also peripheral nervous systems (PNS). Abuse of CNS stimulants may cause psychosocial, psychiatric and medical deterioration. Since then, it leads to confusions in drug tolerance, dependence, sensitization, and even causes withdrawal syndrome [21]. Stimulants cause initial effects on the users including alertness or wakefulness, awareness, motivation, productivity, endurance, arousal but also increase heart rate, blood pressure, and decrease desire for sleep and eating. Addiction to stimulants can be observed by expression of depression, torpor, confusion and grief until the body re-establishes its normal state [4]. It can be explained by the reduction significantly in production of natural body chemicals triggered distinct functions that caused by the stimulants. Animal discrimination and self-administration models, which have high sensitivity, have been used for screening of stimulants although the specificity is low [22].

Amphetamine, which was used clinically in 1932, was first synthesized in 1887. Nowadays, amphetamines (methylphenidate, 
methamphetamine and amphetamine) are commonly used like drugs to treat attention deficit hyperactive disorder (ADHD). Nevertheless, these drugs are likely to be highly addicted due to their CNS stimulant effects. Both amphetamine and methamphetamine are equally effective as CNS stimulants; however, methamphetamine is easier to be found in clandestine market than amphetamine due to its ease of synthesis from pseudoephedrine or ephedrine [23]. See Figure 1.1 for chemical structure of amphetamine, methamphetamine and MDMA.

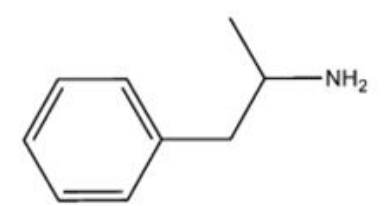

Amphetamine

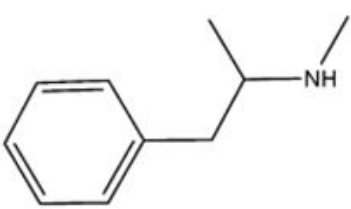

Methamphetamine<smiles>CNC(C)Cc1ccc2c(c1)OCO2</smiles>

MDMA/ecstasy

Figure 1.1: Chemical structure of amphetamine, methamphetamine and MDMA/ecstasy [9]

Abuse to Amphetamines: Amphetamines are structurally similar to phenylethylamine (Figure 1.2). They produce their clinical effects by modulating central and peripheral catecholamine neurotransmitter system consequently causes sympathomimetic effects. Toxicity triggers clinical symptoms including hypertension, hyperthermia, hyper-arousal, tachycardia, paranoia, hallucination and agitation [4]. It can be observed epilepsy and coma that may occur due to overdose and electrolyte abnormalities. Urine drug screening can be used as a reliable diagnosis to test for amphetamine and methamphetamine. When the users get agitation due to amphetamine/methamphetamine effects, benzodiazepines are first line agents will normally be used to treat. Nevertheless, it is strictly recommended not to use beta-blockers to control hypertension-induced amphetamine effects because the toxicity may be worsened by potential alpha-receptor stimulation [24].

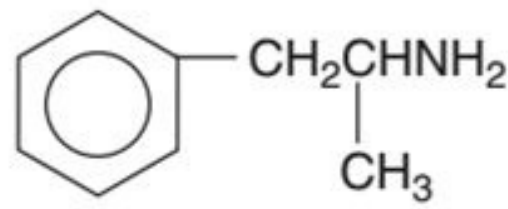

Amphetamine

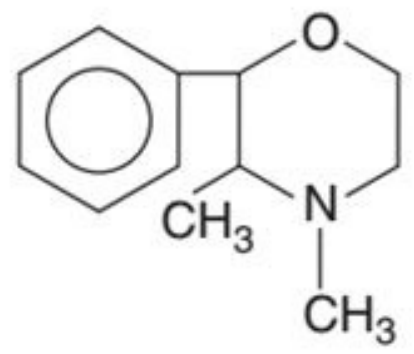

Phendimetrazine

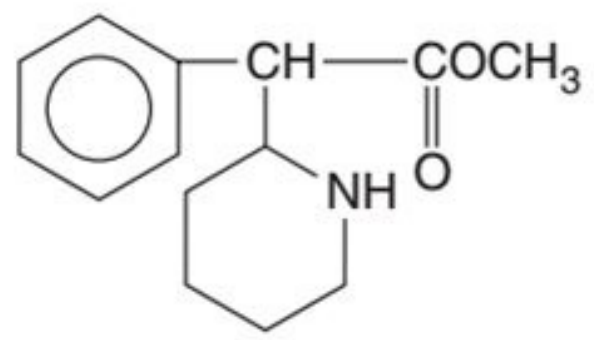

Methylphenidate

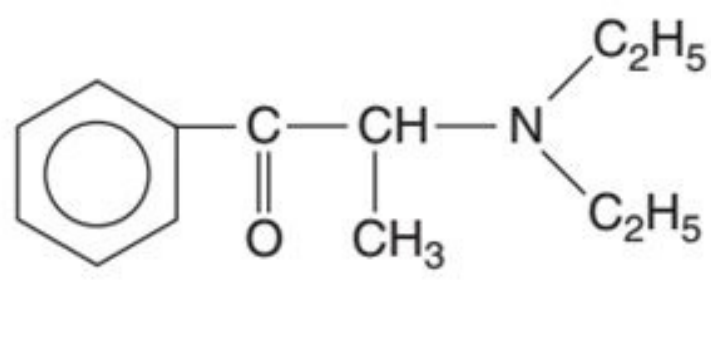

Diethylpropion

Figure 1.2: Structural formulas of amphetamine and related stimulant drugs [25]

Amphetamine and methamphetamine can be eliminated via real and hepatic clearance with estimated half-life ranging from 6 to 12 hours. In addition, they are excreted as parent drug in the urine while, MDMA has estimated half-life of 7 hours [4]. Table 1.3 summarizes common abused drugs along with their metabolites.

Abuse of amphetamines (amphetamine, methamphetamine and MDMA) can cause fatalities and the diagnosis from studies, using gas chromatography/mass spectrometry (GC/MS), shown that the amphetamines abused-related fatalities relatively associated with these drug-contained concentrations of higher than $0.5 \mathrm{mg} / \mathrm{L}$ but deaths also can occur with of that blood level of 0.05 $\mathrm{mg} / \mathrm{L}$, though usually along with other substances or significant natural illness [4]. Another testing also routinely used to detect amphetamine, methamphetamine and MDMA in clinical laboratory is immunoassays [26]. To confirm whether methamphetamine presents in urine, GC/MS has been used to test for its derivatives, normally amphetamine appear in the sample or not [4,26]. 


\begin{tabular}{|c|c|}
\hline Drug & Metabolites \\
\hline Amphetamine & $\begin{array}{l}\text { Para-hydroxyamphetamine, benzoic acid, and } \\
\text { conjugates } \\
\text { Significant amount of amphetamine is also recovered in } \\
\text { the urine }\end{array}$ \\
\hline Methamphetamine & $\begin{array}{l}\text { Amphetamine, 4-hydroxyamphetamine, } \\
\text { 4-hydroxymethamphetmine, benzoic acid; unchanged } \\
\text { methamphetamine also recovered in the urine }\end{array}$ \\
\hline MDMA & $\begin{array}{l}\text { 3,4-Methylenedioxyamphetamine (MDA), 4-hydroxy- } \\
\text { 3-methoxyamphetamine (major metabolite also } \\
\text { excreted in urine as glucuronide or sulfate conjugate), } \\
\text { 3,4-dihydroxy-methamphetamine, and 3-hydroxy- } \\
\text { 4-methoxymethamphetamine }\end{array}$ \\
\hline Cocaine & $\begin{array}{l}\text { Benzoylecgonine, ecgonine methyl ester, nor-cocaine } \\
\text { (minor metabolite) }\end{array}$ \\
\hline Heroin & $\begin{array}{l}\text { 6-Monoacetyl morphine (also known as 6-acteyl } \\
\text { morphine; marker of heroin abuse), morphine }\end{array}$ \\
\hline Morphine & $\begin{array}{l}\text { Morphine-3-glucuronider (major metabolite; inactive) } \\
\text { and morphine-6-glucuronide (active metabolite) }\end{array}$ \\
\hline Codeine & Morphine, morphine-3-glucuronide \\
\hline Hydrocodone & Hydromorphone \\
\hline Oxycodone & Oxymorphone \\
\hline Methadone & $\begin{array}{l}\text { 2-Ethylidine-1,5-diemethyl, 3,3-diphenylpyrrolidine } \\
\text { (EDDP) }\end{array}$ \\
\hline Propoxyphene & Nor-propoxyphene \\
\hline $\begin{array}{l}\text { Marijuana } \\
\text { ( } \Delta^{9} \text {-tetrahydrocannabinol) }\end{array}$ & 11-Nor-9-carboxy- $\Delta^{9}$-tetrahydrocannabinol \\
\hline Phencyclidine (PCP) & $\begin{array}{l}\text { Cis and trans-1-(1-phenylcyclohexyl)- } \\
\text { 4-hydroxypiperidine, 4-phenyl- } \\
\text { 4-piperidinocyclohexanol, and their conjugates }\end{array}$ \\
\hline Amobarbital & 3-Hydroxy amobarbital \\
\hline Pentobarbital & 3-Hydroxy pentobarbital \\
\hline Secobarbital & 3-Hydroxy secobarbital \\
\hline $\begin{array}{l}\text { Lysergic acid diethylamide } \\
\text { (LSD) }\end{array}$ & 2-Oxo-3-hydroxy lysergic acid diethylamide (O-H-LSD) \\
\hline
\end{tabular}

Table 1.3: Common abused drugs and their metabolites [4]

\begin{abstract}
Abuse of Caffeine: Caffeine, naturally found in coffee and tea, and small amount in cocoa solids and chocolates, is included in energy drinks and soft beverages. It is one of the most common stimulants and extensively used psychoactive drug in the world although it is restricted for sale and usage in a few jurisdictions. It has clinical effects and been used in some medications to enhance the effects of the primary ingredient or minimize its adverse effects (especially sleepiness). There are tablets containing certain and standardized concentration of caffeine in the market. Caffeine triggers mechanism of action which differs from stimulants to another through inhibition of adenosine receptors which are large driver of sleepiness or drowsiness [11,27]. Caffeine was indicated to inhibit effect of adenosine receptors on dopamine receptors $[4,28]$ and increase striatal dopamine in animal models [29] though the implications in human have not been clarified yet. In reverse to other stimulants, it has no addictive potential.

Coffee consumption is nowadays common around the globe and its safety in use has also been questioned. To date, there are more than 500 research works with epidemiologic evidence have been conducted to investigate the coffee consumption in associated with cancers in different sites. It was indicated that it appeared to be strong and consistent protective association in relation with endometrial cancers and hepatocellular cancers and in borderline protective association in relation with colorectal cancer. In cases of ovarian, gastric, prostate, kidney, pancreatic and breast cancer, it has shown no association. In some population in specific sites it appeared to be associated with bladder cancer in men. Coffee consumption in mother during pregnancy with high dose of daily consumption in association with childhood leukemia was ambiguous [30]. Moderate coffee consumption helps against Alzheimer's disease however the evidence is unassured [31,32]. A decrease in risk of cardiovascular disease [33] as well as type 2 diabetes [34] is possible with daily use of caffeine with moderate dose. It has been studied and concluded that habitual consumption of 3 cups of coffee a day did not increase the risk of high blood pressure compared to 1 cup/day; however, a slight increase in risk seems to
\end{abstract}


be associated with mild to moderate consumption of 1 to 3 cups/day [35]. Caffeine has been found to increase the effectiveness of treatment options of acute migraine headache [4].

\begin{abstract}
Abuse of Cocaine: Cocaine, a serotonin-norepinephrine-dopamine reuptake inhibitor (SNDRI), another name of triple reuptake inhibitor (TRI), naturally found in the leaves of Erythroxylum coca shrub that grows in abundantly South America (including Peru, Columbia and Bolivia) and other sites of the world with lesser extent. In the late of 1700s, Albert Neimann extracted and then evaluated the anaesthetic properties of cocaine, which is believed to be the consequence of reversible blockade of nervous impulse conduction by inhibition of sodium ion movement inside the cell membrane. It is commonly found in white crystalline powder form in North America, Europe and some part of Asia. The clinical use of cocaine is in association primarily with operating procedures including the manipulation of mucous membranes [36]. Although cocaine has been clinically used as anaesthetic in ophthalmology, it is not ordinarily prescribed as a stimulant with its property, therapeutically. It is strictly controlled in most sites globally for its sale and consumption due to its highly potential addictive property. In fact, cocaine was initially used with recreation purpose, however, it is more addictive than amphetamine [4].
\end{abstract}

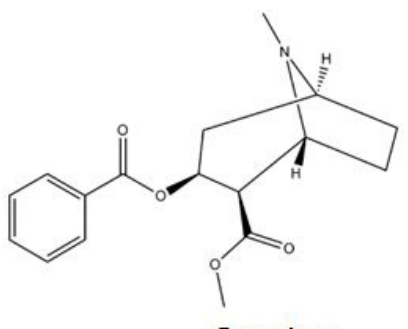

Cocaine

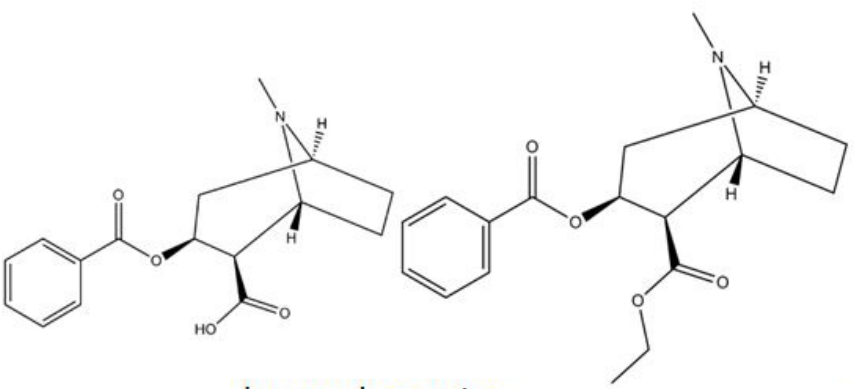

benzoylecgonine

Figure 1.3: Chemical structures of cocaine, benzoylecgonine and cocaethylene [27]

cocaethylene

In clandestine market, cocaine preparations sold as hydrochloride salt, normally with $50 \%$ cocaine contain because the manufacturers blended with agents such as sugar, lactose, mannitol for more profits. Cocaine powder and crack cocaine are other forms of cocaine that can be found in illegal market. The latter is known as a freebase of cocaine which makes a characteristic sound when smoked. Cocaine has been used with diverse ways including smoking, snorting, oral taking or intravenous. It has high potential addiction because it makes users get feeling of elevated mood, euphoria, enhanced sexual energy. Nevertheless, in some cases it has various undesirable effects such as delirium, psychosis, hallucination or paranoia [4].

Addiction to cocaine becomes a serious healthcare issue globally. In the US, approximately 25-30 million individuals have used cocaine and more than $20 \%$ of this number is using it on a regular basis. Cocaine addiction is harmful to human health even leads to death due to its unpredictable cardiotoxic effect. Regularly abuse to cocaine is associated with various cardiovascular diseases and disorders including hypertension, endocarditis, cardiomyopathy, myocarditis, arrhythmias, myocardial infraction. It is also associated with cerebrovascular aneurysm. At the presynaptic level in the PNS and CNS, it blocks the reuptake of catecholamines including dopamine and norepinephrine. Patients with cocaine cardiotoxicity were observed with increase serum catecholamine in the myocardium. It results in stimulation of beta-adrenergic receptors and increase in heart rate. Cocaine anaesthetic effect also causes negative inotropic effect hence affects the heart [37]. In addition to cardiovascular complications, cocaine abuse is also associated with neurological and psychiatric abnormalities including cerebral ischemia, intracerebral haemorrhages, stroke and subarachnoid. Reduction in cerebral blood flow, impaired platelet function, and cocaine-induced vasospasm may result in neurological complications [4]. Women in pregnancy period should be aware of using cocaine due to its devastating effects on the fetus such as miscarry, placenta-associated syndromes, impaired fetal growth or even impaired neurological development affecting to their cognitive and intellectual abilities, behaviours and adverse effects on executive and memory function. However, when it is infrequently discussed between patients and physicians, in turns into an important public health issue [38]. When users abuse cocaine together with alcohol at the same time, even with lower concentration of cocaine also cause fatality. It is because that they two are used simultaneously, coaethylene, an active metabolite of cocaine will form and cause clinical effects [4].

With short half-lie, cocaine is easily absorbeb after snorting within 05 to 1.5 hours. Another common and inactive metabolite of cocaine is benzoylecgonine. It is formed spontaneous hydrolysis of cocaine in vivo, while cocaine is naturally metabolized into ecgonine methyl ester from plasma butylcholinesterase [4]. Other minor metabolites of cocaine include metahydroxy cocaine, metahydroxy-benzoylecgonine, para-hydroxy-benzoylecgonine, and nor-cocaine which is formed by the action of liver enzymes (more in Table 1.3). See Figure 1.3 for the chemical structures of cocaine, benzoylecgonine and cocaethylene.

Many reports have been conducted with wide range of benzoylecgonine and cocaine concentrations in individuals who have died regarding to cocaine overdose. In the report, the percentage of cocaine addicted men (95-98\%) was higher than in women (2-5\%) however there is no signigicant diffference among their ages (29-30 years-old). Of the drug-related deaths, the average cocaine concentration was $0.13 \mathrm{mg} / \mathrm{L}$ [4]. Cocaine asociated mortalities typically invloved multi-drug intoxications among cocaine with other drugs (heroin, amphetamines, cannabis, benzodiazepines) and/or alcohol [39]. Cocaine level in blood can be very high 
for those who had died of cocaine abuse. Cocaine is frequently measursed in clinical laboratories using a screening test aimed at benzoylecgonine. Validation for confirmation can be done by using GC/MS [4].

\begin{abstract}
Abuse of Nicotine
Nicotine is an active component that can be found not only in the leaves of tobacco plant with 0.6-3.0\% of the dry weight, but also in some edible plants including tomatoes, potatoes, and eggplants with very small content $\sim 0.00002 \%$ in their dry weight [40,41]. There are various forms of nicotine in the market including chewing tobacco, cigars, cigarettes and some smoking cessation aids such as electronic cigarettes, nicotine gum and nicotine patches. Nicotine is highly addictive stimulant and widely used globally due to its relaxing and stimulating effects [42]. It exerts its effects as an agonist with nicotinic acetylcholine receptor (nAChRs) which decrease expression of monoamine oxidase in the brain and increase activity of dopaminergic neurons in the midbrain reward system [43]. Among various sources of nicotine, tobacco is overally most harmful to user with $13 \%$ percentage higher than amphetamines, only 3\% lower than cocaine and ccording to a multi-criteria decision analysis by group of researchers, nicotine was assessed and ranked the sixth most harful in total twenty harful and addictive drugs [44].
\end{abstract}

\title{
Abuse of Khat
}

Khat (Catha edulis Forsskal) is a evergreen flowering plants orginally from Arabian Peninsula and African Horn. People in these sites have habitual and traditional chewed the Khat leaves firstly for its CNS stimulant effect and secondly for alleviation of depression and relief of fatique [45]. In addition, it has also been used to enhance the efficiency of completing tasks of the students in preparation period for exam session as well as of the workers to work more efficient. This study also reported that chewing Khat's leave help control the elevated blood glucose level in diabetics in Yemen. A report in 2008 indicated that Khat was used as an anti-obesity agent [46].

It was classfied as a drug of abuse by WHO in 1980 due to its content of cathinone (Table 1.4), a monoamine alkaloid can cause euphoria, loss of appetite, and excitement. In some countries such as Yemen, Somalia, Ethiopia and Djibouti, it is planted, saled and used legally for individual consumption while it is strictly controlled in other countries including the US, Germany, Canada and some others [45]. In fact, in Yemen people chew Khat on a daily basis which accounts for 23\% of total population [47,48]. It cause light to medium psycholical dependence just less than alcohol or tobacco [21] although the WHO does not consider Khat to be seriously addictive $[7,49]$.

\begin{tabular}{|c|c|}
\hline Constituent & Concentration \\
\hline Cathinone & $\begin{array}{c}77.7-342 \mathrm{mg} / 100 \mathrm{~g} \\
36-114 \mathrm{mg} / \mathrm{gm}\end{array}$ \\
\hline Cathine & $83-120 \mathrm{mg} / \mathrm{gm}$ \\
\hline Norephedrine & $8-47 \mathrm{mg} / \mathrm{gm}$ \\
\hline Tannins & $0.82-9.69 \mathrm{mg} / 100 \mathrm{gm}$ \\
\hline
\end{tabular}

Table 1.4: The most common components of Khat [44]

\section{CNS Depressants of Abuse}

Depressant, also called central depressant is drug that diminishes neurotransmission levels, which reduce or depress stimulation or arousal in the CNS. Occasionally, it refers to as tranquilizer, antipsychotic and/or sedative which reduce the symptoms of mental illness as well as slow brain activity. Hence, it is used to treat sleep disorders and anxiety. Depressant drugs include alcohol, tranquilizers, benzodiazepines, cannabis, barbiturates and opioids [50]. Most of those drugs trigger their effects by affecting the neurotransmitter gamma aminobutyric acid (GABA) which play roles in communication of brain cells to each other consequently decrease the brain activity, and inhibition of monoaminergic or glutamatergic activities. When user takes depressant(s), GABA activity will be pushed up, hence produce calming or drowsy effect [51]. Today, depressants are widely used globally in both forms of non-prescription substances and prescription medicines. They can cause pain relief, anxiolysis, ataxia, cognitive/memory impairment, anticonvulsant effects, respiratory depression, lowered heart rate or blood pressure, muscle relaxation, and even complete anaesthesia or mortality at high doses [7]. Among the depressants, alcohol is the most prominent depressant which cause serious health problem, especially in teenagers and young adults [52,53]. Long-term use of depressants can cause the users tolerant to the drugs, since then require higher doses to get the initial effects. Moreover, when they minimize or stop the drug dose, a withdrawal will ensue due to the reuse of brain activity and may lead to consequences of seizures or some harmful effects [7].

\section{Alcohol Abuse}

Alcohol, in conjunction with tobacco and caffeine, is a drug widely used and socially accepted in most of countries around the world [54]. It is much used in many social celebrations, festivities, and religious ceremonies. Alcohol use has become a feature of almost all tribes, cultures and societies across human being, although the motivation for use, the social control of usage differs from 
cultural group, societies, and historical periods [55]. However, there are laws and regulation for its manufacturing, production, sale, promotion, and consumption in more than 100 countries. Among recreational drugs, ethanol is considered as the oldest one still used by human because the fermentation and brewing of alcoholic beverages from plants have been done since 5000 BC [54]. According to the variation in grain and fruits used for making, brewing and distillation processes, there are three general classes of alcohol beverages including spirits (distilled beverages), beer and wine [7].

Alcohol use differs among various sites within countries and among countries. Since 1990, worldwide consumption of alcohol has been fairly stable, except for some Islamic countries where alcohol sale and use is illegal [4,54]. According to WHO report, in 2005 an average alcohol consumption by teenager at 15 years-old was $6.13 \mathrm{~L}$ globally, higher with $12.18 \mathrm{~L}$ in Europe and lower with $0.65 \mathrm{~L}$ in the Eastern Mediterranean [7] while the estimated calculation in UK was 10.2L per person with age of 15 and higher in 2010 [56]. Those differences can be explained by abstention rates, which are related to the number of Muslim portion in that country as well as between men and women. In different word, the larger the portion of Muslim in a population, the lesser the number of drinkers is, such as in South Asia and North Africa. The abstention is also lower among men than women [7]. However, the per capita consumption is relative because there is a significant contribution of the illicit and/or unrecorded production of homemade alcohol (potential contaminants and lack of quality control) to total alcohol consumption [57].

Alcohol misuse and its negative consequences include short-term and long-term health issue and social problems for users, their family and the society. It was described as one of the world's leading health risks among 60 major diseases in the world, accounting for $4-5 \%$ of the worldwide burden of injuries and diseases and causing premature death of 2.5 million annually [7]. In men with ages of 15 to 59, alcohol is the leading cause of death. Both chronic and acute alcohol use affects to user's heath, which is also directly affected by patterns of drinking and average volume of alcohol use [58]. Psychologically and physically dependent sign of alcohol including daily drinking, recognized withdrawal syndrome or increased tolerance may lead to long-term health problems which consequently attribute to liver cirrhosis (approximately 50\% circumstances), cancers ( 22\%) and other cardiovascular diseases $(\sim 14 \%)$ [4]. Moreover, alcohol misuse also physically implies amnesia, anxiety, depression, insomnia, acute alcohol poisoning, brain damage, cardiac arrhythmia, high blood pressure, cardiomyopathy, gout, diabetes, obesity, nutritional deficiencies, hepatitis and gastritis [54,59]. Certainly, it is difficult to disentangle alcohol use nowadays because of its causal role in web of social issues and human health [60]. The social problem related to alcohol misuse were also been noticed in that report, including aggression, disorder and public drunkenness. According to Orford and his co-workers, there are approximately 100 million family members in the world were directly or indirectly affected by alcohol addiction, resulting in suffering, pain and stress [61]. Last but not least, alcohol and abuse and its economic impact have been reported in term of injury, illness, accidents, lost productivity. To respond to alcohol abuse, there are common practices which have been done by individuals, researchers, health and social services and legislative bodies in order to overcome alcohol dependence as well as achieve positive outcomes related to health and well-being. For instance, increase in price in licensed premises and taxation may help reduce alcohol demand from the population; restriction on availability of alcohol beverage in term of minimum purchase age, types of alcoholic beverages sold, density of outlets and trading hours to reduce alcohol-related problems at population level; framework to address alcohol misuse suggested from health and social services [54].

\section{Opioid Abuse}

From ancient time, opium has been used in medicine for paint management at a certain dose, including morphine, thebaine and codeine [62]. Natural opiates such as codeine and morphine have been used to relieve pains. Thebaine, a semi-synthetic opiate, has been used as raw material to synthesize naloxone, buprenorphine, oxymorphone, and other associated semi-synthetic opiates. In modern medicine opioids have been synthesized and used based on pharmacological action of natural opiates. Depends on medicinal value, opioids are divided in to "Schedule" ranging from I to IV with lessen medical value to medical ones (Table 1.5 for common opioids in the US) [4]. Among various opioids, methadone, meperidine and fentanyl are common synthetic ones. They are widely used to relieve pains and in treatment for non-cancer and cancer patients [62]. Nevertheless, "opioids" is a term refers to compounds that render their pharmacological possessions by acting as agonists of opiate receptors [4]. Naltrexone and naloxone, two common opioid antagonists have been used to treat for patients with opiate overdose and sometimes, in conjunction with the use of another opioid to lessen addictive potential of prescribed opioid [63].

There are three opioid receptors, kappa, delta and mu interact with opioids and trigger the pharmacological effects of opioids (normally produce analgesic effect). They can be found post-synaptically or pre-synaptically (depend on cell type) in the spinal cord dorsal horn, cortex, thalamus and brain stem. In addition, they also interact with the endogenous opioids including dynorphins, leu-enkephalins and beta-endorphin [64]. Many studies conducted with animal models indicated that the euphoria and addictive effects induced by opioids are also related with the interaction between the opioids and the mesolimbic dopamine system. Morphine-like opioids (such as codeine, meperidine, oxycodone, levorphanol, methadone, and hydromorphone) and morphine itself interact with mu receptor to trigger pharmacological effects. Butorphanol, nalbuphine and pentazocine are mixed agonist of opiate receptor though buprenorphine is a partial opiate receptor agonist. Only naloxone which is commonly used to treat opioid overdose, is antagonist of all three opiate receptors [4]. 


\begin{tabular}{|c|c|c|}
\hline Drug & Nature & Schedule drug \\
\hline Codeine & Natural opiate & Schedule II \\
\hline Morphine & Natural opiate & Schedule II \\
\hline Dihydrocodeine & Semisynthetic & Schedule II \\
\hline Hydrocodone & Semisynthetic & Schedule II \\
\hline Hydromorphone & Semisynthetic & Schedule II \\
\hline Oxycodone & Semisynthetic & Schedule II \\
\hline Oxymorphone & Semisynthetic & Schedule II \\
\hline Buprenophine & Semisynthetic & Schedule III \\
\hline Fentanyl/alfentanil/sufentanil & Synthetic & Schedule II \\
\hline Meperidine & Synthetic & Schedule II \\
\hline Methadone & Synthetic & Schedule II \\
\hline Levorphanol & Synthetic & Schedule II \\
\hline Pentazocine & Synthetic & Schedule IV \\
\hline Propoxyphene & Synthetic & Schedule IV \\
\hline Tapentadol & Synthetic & Schedule II \\
\hline Tramadol & Synthetic & Schedule IV \\
\hline Table 1.5: Common opioids in the US $[4]$ & \\
\hline
\end{tabular}

Morphine has pharmacologically analgesic effect within 4-6 hours. Its active metabolite, morphine-6-glucuronide is normally excreted in urine in patients but can be gathered in in blood. Another inactive metabolite of morphine, morphine 3-glucuronide is also secreted in urine in users. UGT2B7 is the major isoform of uridine diphosphate glucuronosyltransferase enzyme, which is responsible for conjugation of glucuronic acid (both 6-and 3-morphine glucuronide) with morphine. The metabolism of morphine into codeine is made by liver isoenzyme named CYP2D6. Codeine has analgesic effects by its active metabolite morphine hence it is considered as a pro-drug. Patients have no or deficiency of CYP2D6 enzyme will get lesser pain relief from codeine therapy $[4,11]$.

Heroin, normally in form of white or brown powder, is classified as Schedule I drug due to its no valuable use in medicine. It was synthesized from morphine by Alder Wright in 1874 and since then become a popular addictive drug worldwide. Heroin metabolites include 6-monoacetylmorphine (or 6-acetylmorphine or marker of heroin abuse) and morphine (by hydrolysis of ester linkage), finally (Table 1.3). The metabolism of heroin is made by liver enzymes carboxylesterase 1 and 2, and serum pseudocholinesterase. Heroin can be used by injection into the vein, smoking, snorting (or inhaling) and the onset effects can be last long for two hours after taking the drug [65]. They include decrease in breath or respiratory depression, euphoria, abuse, pneumonia, constipation, blood borne infections, infected heart valves and abscesses. By injection directly into the vein, heroin trigger effects 2-3 times higher than morphine with similar dose use and the withdrawal symptoms can appear just within hours after previous use. Heroin abuse has been treated by medications (with naltrexone, methadone and/or naloxone) and behavioural therapy [63]. According to World Drug report 2016, there was an estimated number of 17 million people use heroin worldwide in 2015 [66] and 122.000 deaths annually [67]. Statistics from 1998 to 2007 showed that the total number of opiates users has increased and since then it has remained less or more stable [66]. In the US, this number is approximately $1.6 \%$ of the total national population [63]. Testing for heroin abuse is done by detecting the 6-monoacetylmorphine in users to confirm. Figure 1.4 shows the chemical structures of heroin, oxycodone, codeine and morphine.

Oxycodone, morphine, methadone, fentanyl, buprenorphine are strong opioids, which are normally used to treat severe pains while other weak opioids including tramadol, propoxyphene and codeine are commonly used for treating moderate or mild pains in patients. Nevertheless, respiratory depression and over-sedation are symptoms that can be found as fatal poisoning resulting from opioids use in patients. There are intersections between toxic and therapeutic blood concentration of opioids, controversially. In fact, poisoning from weak opioids including tramadol and codeine may be associated with high blood codeine and/or tramadol concentration while poisoning due to strong opioids use such as methadone is associated with methadone concentration in blood in therapeutic levels [4]. Sedative-induced opioids in conjunction with alcohol use are frequently related to fatal opioid poisoning [68].

Due to the pharmacological properties of opioids, they can be detected by opiate immunoassays or not. For instance, morphine and codeine can be detected for their presence while other opioids including fentanyl, meperidine, methadone, propoxyphene, hydrocodone, hydromorphone, oxymorphone and oxycodone cannot be detected. There are also some specific immunoassays used for detection of fentanyl, methadone, hydromorphone, hydrocodone, and oxycodone according to their poor crossreactivity. Morphine can be detected and found in the urine of heroin addicts because heroin is metabolized to morphine. Opiate 
immunoassays in some cases, is very sensitive to detect opiate with very low concentration even at $2000 \mathrm{ng} / \mathrm{mL}$, however, morphine and codeine also present in urine in users [11].

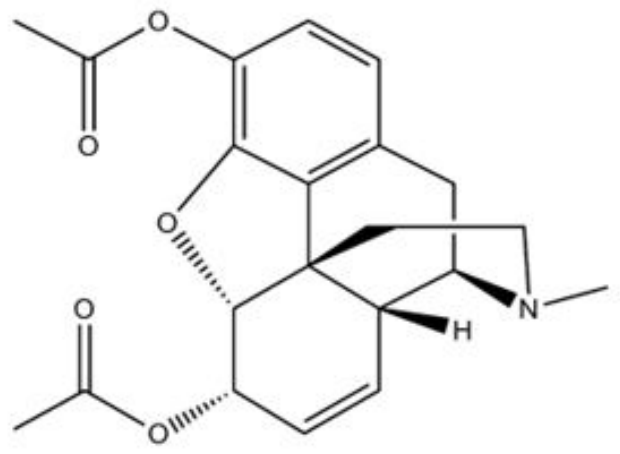

Heroin

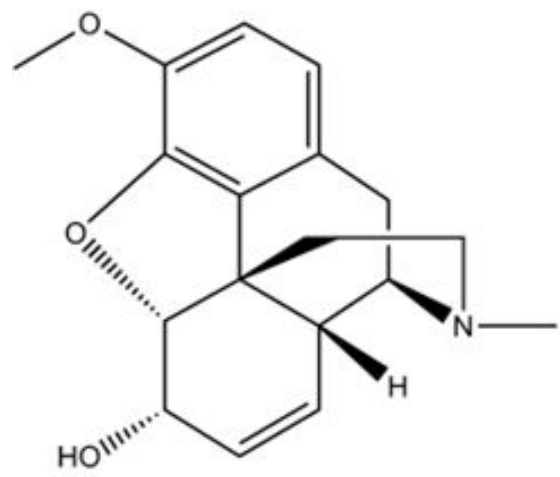

Codeine

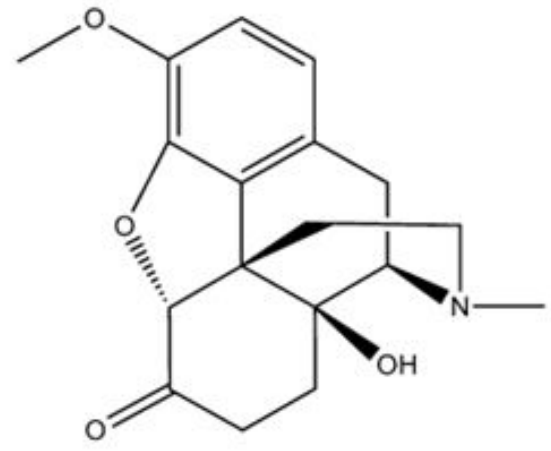

Oxycodone

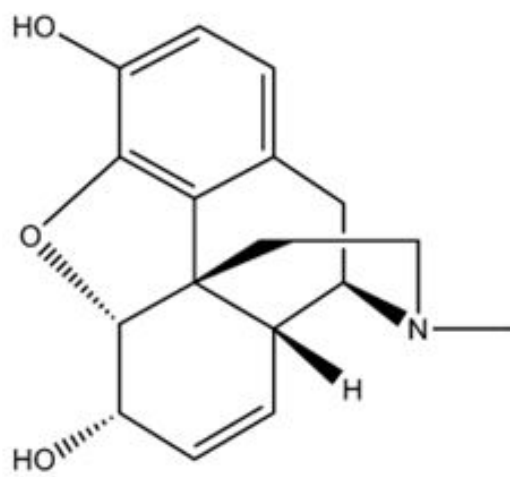

Morphine

Figure 1.4: Chemical structures of heroin, oxycodone, codeine and morphine [4]

\section{Cannabinoid Abuse}

Cannabinoid, a substance found in the Cannabis sativa plant, is considered as a depressant due to its psychoactive effect such as decreased tiredness and alertness, sedation and muscle relaxation. Since prehistoric times, that cannabis plant (marijuana) has been used by smoking and gradually become one of the most abused drugs in the US. In some states of the US including Washington and Colorado, cannabinoid use is legal in recreational and medicinal purposes which lead to more marijuana use among adolescents in these states. In addition to smoking form of marijuana as a common route of administration, edible form also can be found in the market such as marijuana tea. Most of parts of the C. sativa plant contain cannabinoids, include seeds, flowers, leaves, stalks and resin (in female plant only). Apart from cannabinoids, there are more than 100 cannabinoids-likecompounds also can be isolated from the C. sativa plant in which $\Delta^{9}$-THC, also named delta-9-tetrahydrocannabinol is the most abundant psychoactive substance (Table 1.3). This component is partial agonist at both cannabinoid receptor 1 and 2, which are placed in the brain and hence execute its pharmacological effect. In contrast, non-psychoactive cannabinoid component can be extracted from the plant is cannabidiol, which is not really agonist at cannabinoid receptors. Depends on the strains of the $C$. sativa plant, cultivation methods, preparation and extraction approaches, the $\Delta^{9}$-THC amount may differ expressively. However, a common smoke can contain about 150 cannabinoids. Resin from female plant can be used to prepare hashish, which contains up to $300 \mathrm{mg}$ of cannabinoids with a single dose and contain more active components than marijuana in the same joint and dose [11].

To date, cannabis is mainly used in medical purposes to treat AIDS and cancers patients, and sometimes in some cases for noncancer patients. Nevertheless, there are limited number of studies and clinical trials to assess the safety and efficiencies of the cannabinoids in medical use. Marinol, synthetic marijuana was introduced into market to treat vomiting and nausea symptoms when patients are under chemotherapy [4]. Moreover, the $\Delta^{9}$-THC and its derivatives have also been sold for medical use [69]. Despite of its potential therapeutic benefits, cannabis has disadvantageous possessions on heart (myocardial and arrhythmia infarction), lung (lung cancer and/or bronchitis), psychiatric issues (such as schizophrenia, psychosis, depression, and anxiety), and brain and CNS. The acute complications of marijuana use are mostly respiratory and cardiovascular depression [70].

By smoking, lungs will rapidly absorb about $50 \%$ of the $\Delta^{9}$-THC in the mainstream of smoke, from the cannabis into bloodstreams, resulting in feeling of users such as change in perception and euphoria. However, this absorption ratio is lesser by oral taking of cannabinoids (about 25-30\%). The psychoactive effect can be observed within 15-30 mins after use, and can last long for 2-3 hours. 
The lipophilic property of molecule makes it has half-life is almost 07 days, and it takes about more than 30 days to eliminate the substance out of user's body completely. Both 11-hydroxy- $\Delta$ 9-tetrahydrocannabinol (THC), an active metabolite of the $\Delta^{9}$-THC and 11-nor-9-carboxy- $\Delta^{9}$-tetrahydrocannabinol (THC-COOH) are metabolized by liver enzymes including CYP2C9, CYP2C11, and CYP3A4 [4,69]. Figure 1.5 shows the chemical structure of THC-COOH and THC.

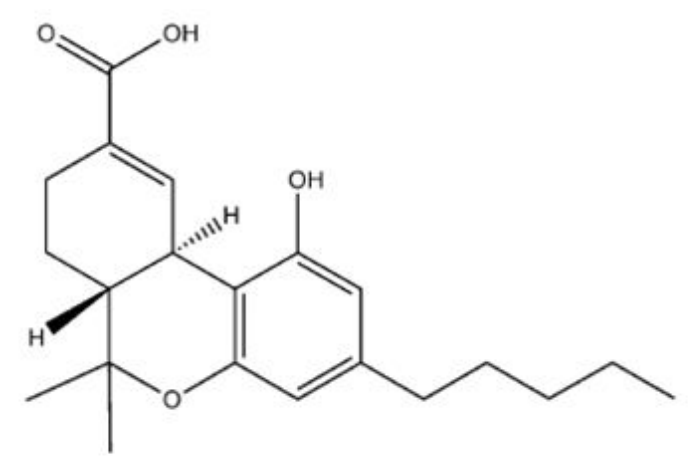

THC-COOH

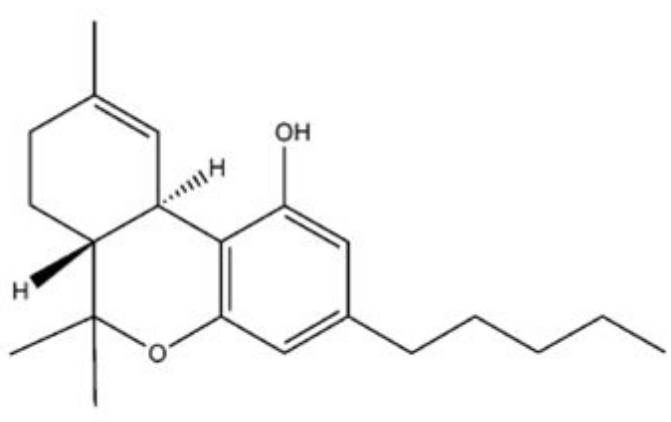

THC

Figure 1.5: Chemical structure of THC-COOH and THC [9]

There are various consequences and effects from smoking marijuana including cognitive impairment, impairment if psychomotor functions, disorder in the respiratory system and cardiovascular system, emphysema and bronchitis, bronchogenic carcinoma [71], stroke [72]. Cannabinoid is normally confirmed in urine toxicology test with the presence of THC-COOH. Also, GC/MS analysis has been used to test and confirm the presence of cannabinoid [69].

\section{Anaesthetics Abuse}

Ketamine and phencyclidine are two major anaesthetics abused, which were initially used to pre-induce anaesthesia and tranquilizer for animal. Phencyclidine has been sold in various form including liquid, crystal, and powder with different ways of use such as subcutaneously or intravenously injecting, smoking and snorting [11]. Anaesthetics trigger effects very fast, with small dose of $15 \mathrm{mg}$ of phencyclidine, it can inhibit serotonin, norepinephrine, and dopamine reuptake; consequently increase those receptor's production by motivating tyrosine hydroxylase. In addition to reducing perception of pains, anaesthetics may also cause hypertension, tachycardia, nystagmus, and violent behaviour. Hydroxy metabolites of phencyclidine are listed in Table 1.3. Phencyclidine is normally detected in urine toxicology screening [4]. Automated analyser and immunoassays also have been used to detect phencyclidine presence however there are intersection between phencyclidine concentration and dextromethorphan in the body' user, which can be found in some non-prescription cold and cough medications, make the result incorrect and unreliable [73].

\section{Benzodiazepines Abuse}

Benzodiazepines are a group of mild tranquilizers commonly referred to as "Benzo", including oxazepam, diazepam and chlordiazepoxide. It is widely used to treat anxiety, stress, muscle spasms, agitation, seizures, insomnia and at high doses, help cure epilepsy, alcoholism. They are all CNS depressants and increase the effect of GABA at the GABAA receptors. Long-acting benzodiazepines are preferred to treat anxiety while short and intermediate-acting ones are recommended to treat insomnia [74]. Benzodiazepines are also relatively addictive and cause decrease in cognitive ability when using overdose. Moreover, they do, in conjunction with alcohol and opioids use, causes severe consequences. Hence, they should not be prescribed continuously for more than one month [74].

\section{Barbiturate Abuse}

Barbiturates are CNS depressants used in medical use as sedative hypnotic drugs. About 50 drugs out of total of more than 2500 synthesized derivatives of barbituric acid have been used for clinical purposes. They are categorized into sub-group by their duration of action including ultra-short-, short -, intermediate-, and long-acting types. The latter includes mephobarbital (Mebaral) and phenobarbital (Luminal), categorized as Schedule IV drugs have been used as anticonvulsants and are rarely addictive. The ultrashort acting barbiturates including methohexital (Brevital), thiamylal (Surital), thiopental (Pentothal) have been used in clinal purposes due to their effects of producing anaesthesia in a few minutes after intravenous injection. The short- and intermediate 
acting ones, categorized as Schedule III drugs, including aprobarbital (Alurate), talbutal (Lotusate), butabarbital (Butisol), butalbital (Fiorinal) which can be used to treat insomnia and achieve preoperative sedation produce the effect within 15 - 40 mins after oral taking and last long for approximately 6 hours. Other short- and intermediate acting barbiturates are categorized as Schedule II drugs include secobarbital (Seconal), pentobarbital (Nembutal), amobarbital (Amytal). Main metabolites of some barbiturates (secobarbital, pentobarbital, amobarbital) are specified in Table 1.3, which are metabolized by the liver enzymes [4]. Barbiturates trigger their hypnotic effect by enhance GABA activity, which plays significant role in anxiety pathophysiological disorders, resulting in inhibiting of synaptic transmission. Chronic injection or taking of barbiturates causes dependence [75]. Routine urine toxicology can be tested to confirm for the presence of barbiturates.

\section{Drug of Abuse - A Current Issues with Social and Economic Abundances Worldwide}

The term "drug of abuse" is becoming popular and being noticed by people around the world. This term together with alcohol addiction is an important human health problem worldwide [76]. It is considered as a chronic disease since an addict seeks and uses drug out of control regardless harmful consequences. This is considered a brain-related disease, because it leads to changes in the brain structure and how it works. Brain changes due to repeated drug use may cause an addict lost their self-controlled and they cannot resist a strong restless desire to take drugs. Moreover, addiction can lead to harmful behaviours in people abuse to drugs, such as theft, murder, violence and other social evils. In addition, those addicts who have gone through recovery from drug addiction over a lengthy period still have considerable risk of relapsing. Hence drug abuse can be considered as a relapsed disease which is costly and forced to control.

There are a lot of negatively short-term and long-term effects from using illicit drugs either by disabilities or other non-infectious and infectious diseases. According to a statistic in 2010, there was more than 3.6 and 16.4 million of premature death and live disability life, respectively [63]. Back to 1900s till 2010s, cocaine, amphetamine and cannabis were mainly global burden of illness which is predominantly due to population growth. Antagonistically, it is not true for the case of opioid abuse, which presented most to the burden of illness. Different geographic areas have different drug addictions, for instance, Latin America, North America and Africa have high drug abuse of cannabis while opioids use being more prevalent in Caribbean islands and in Latin America [4]. The adverse consequences that the addicts must suffer are the devastation of their health.

\section{Drug of Abuse is a Developmental Disease of the CNS}

Drug addiction, one of CNS diseases or disorders, is a disorder of the brain's reward system which incurred through epigenetic and transcriptional mechanisms [77]. Chronically high levels of exposure to addictive substance (when user smokes or injects them) will entail abuse syndrome. It erodes the way critical brain structures interact to inhibit and control behaviors related to drug consumption. The effects from drugs to people is strong and the rewards from them even last longer than the natural ones. This motivates people to take drugs more and more to gain that powerful reward. Long-term drug abuse impairs brain functioning accordingly. Drug of abuse mend signaling of intracellular messengers, and more important, the neurotransmitter systems [6,77]. The abused user normally feels depressed, lifeless, flat and less pleasurable than before they take and abuse drugs. This is because when they addicted to drugs, their brain adjusts, produces less dopamine, reduces the number of receptors which receive signals; as a result dopamine's impact on the reward circuit of their brain may become unusual low. To gain pleasure, the user need to take even more drugs (dose and frequency) which leads to addiction and it is like a vicious cycle. The tolerance effects make the user always want to seek out and take drugs compulsively.

\section{There is a Significant Need for Study of Drug Abuse and Addiction}

Substance misuse of illicit and prescription drugs, nicotine, alcohol and cocaine leads to financial lost, productivity lost, crime and recovery and/or treatment-related costs in countries around the world. For instance, it costs about $\$ 700$ billion to pay for those health care costs in America [8] and more remarkably there is a death of more than 90,000 people and 480,000 people dues to drug and alcohol abuse and tobacco addiction, respectively in this country [4]. Drug addiction has profound consequences at any age and in different regions. In fact, it may cause disability and born premature in infants; violence, unplanned pregnancies or infectious diseases in teenagers and adolescents; harmful behaviors, inferior performance at works in adults; chaotic or unhappy families, careless to their child and even might set the stage for drug addiction in the next generation in parents [78].

\section{There is no Specific Factor for Drug of Abuse Symptom}

In general, people start taking drugs for a variety of reasons. They might take drug just because they just want to feel good or better or initially because of their curiosity when seeing others are doing it. Most of the addicted drugs in stimulant group, such as cocaine, induce joyful feelings and the users will sense euphoria, self-confidence, more powerful and energy for themselves. While other groups of addicted drugs, such as heroin, cause the euphoria together with satisfactory and relaxing feelings [4]. To someone, drug abuse may be originally caused by stresses at work or society. They want to get out of distress and anxiety by feeling of euphoria-induced substances. From time to time, this feeling might lead to drug abuse, relapsing symptom in the addicts. Others abuse androgenic/anabolic steroids and prescription stimulants to increase their athletic and cognitive performance [7981]. Overall, there will be adverse effects of abusing drugs no matter what the initial purposes of using those substances. And it is difficult to say someone will be addicted to drugs or not. 


\section{The Adverse Effects of Taking Drugs Aside from Making People Feel Good or Better}

Continuous use of the drugs over a prolonged period will detract from the initial positive feelings it brings to the user. Indeed, users gradually post their control in using drugs and tendency of drug abuse and seeking for drugs to use just to feel normal. Other activities become less interesting, and they gave way to craving for drug uses. The telltale signs of abuse symptom are characterized by uncontrolled seeking and taking drug increasing steadily from the users. It must be put in high consideration since moderate drug use also poses dangers. The implication that drug abuse is not only brings directly affects the user but also the surrounding person becomes a burden on society.

At first, the use of the drug was typically voluntary for the user, however, after prolonged use, they gradually lost control and became addicted. Scientists are still on the way to study and analyze changes alter the brain works thereby explain the destructive and compulsive behaviors of the addict. There was a study on brain imaging of the addicts and their finding showed that behavior control, learning and memory, decision making and judgment are typically related to physical changes in the brain [77].

Some people are very easy to be addicted even in their first use of drug ever, while others are not. In fact, the susceptibility of being to drug abuse differs from one to another and there is no specific factor specifies someone will become an addict or not. Generally, the more risk factor he or she has the more vulnerability to drug addiction he or she will be.

\section{Conclusion and Future Recommendation}

Although drug use has essential health benefits, drug abuse is detrimental to human health. Different nonprescription, prescription and other illicit drugs are abused nowadays and when it is along with alcohol, it has been reported to cause mortality in many cases. Illicit drug uses decrease when we have effective interventions and testing, which is a beneficial tool to help youth overcome denial of their substance addiction. Further research should investigate and study more about the relationship between drugs of abuse and physical and neuropsychological diseases for treatments as treatment programs as well as appropriate education in the community is essential for substance-abused users. Understanding the effects of drug abuse and addiction, both CNS stimulants and CNS depressants help researchers and policy-makers to do investigations for drug abuse and mental health issues. The author of this review also highly recommends future study should focus more on effective drug identification programs to avoid abuse ability in users.

\section{Acknowledgement}

The author acknowledge the Vietnam International Education Development-Ministry of Vietnam Education and Training and Dong Nai Technology University-DNTU for funding and supporting the research by scholarship under the Project 911 (20162020) to study drug of abuse and addiction and its consequences to physical and mental health diseases.

\section{References}

1. Raphael CW, Harley YT (2005) Drugs of Abuse. In: Pharmacology and Therapeutics for Dentistry (7 $7^{\text {th }}$ Edn). Elsevier.

2. Gwaltney-Brant SM (2012) Drugs of abuse. In: Small Animal Toxicology Essentials 44: 221-9.

3. Zhang Y, Zhang T, Guo C, Lv J, Hua Z, et al. (2017) Drugs of abuse and their metabolites in the urban rivers of Beijing, China: Occurrence, distribution, and potential environmental risk. Sci Total Environ 579: 305-13.

4. Dasgupta A (2017) Drugs of abuse. In: Alcohol, Drugs, Genes and the Clinical Laboratory (1 $1^{\text {st }}$ Edn). 23-51.

5. Erickson CK (2009) The Science of addiction. National Institute on Drug Abuse, USA.

6. Urbano FJ, Bisagno V, Garcia-Rill E (2017) Arousal and drug abuse. Behav Brain Res 333: 276-81.

7. WHO (2017) World Health Organization. Management of substance abuse, Facts and figures. Geneva, Switzerland.

8. SAMHA (2017) Treatment events and Diseases. Substance Abuse and Mental Health Services Administration. Rockville, USA.

9. NSDUH (2017) National Survey on Drug use and Health. Rockville, USA.

10. Paulozzi LJ, Strickler GK, Kreiner PW, Koris CM (2013) Controlled substances prescribing patterns-prescription behavior surveillance system eight states. CDC 64: 1-14.

11. Roy DT, Goswami R (2016) Drugs of abuse and addiction: A slippery slope toward liver injury. Chem Biol Interact 255: $92-105$.

12. Buttner A (2017) The neuropathology of drug abuse. Curr Opin Behav Sci 13: 8-12.

13. Burke PJ, O Sullivan J, Vaughan BL (2005) Adolescent substance use: brief interventions by emergency care providers. Pediatric Emergency Care 21: 770-6.

14. Di Forti M, Marconi A, Carra E, et al. (2015) Proportion of patients in south London with first-episode psychosis attributable to use of high potency cannabis: a case-control study. Lancet Psychiatry 2: 233-38

15. Di Forti M, Sallis H, Allegri F, et al. (2014) Daily use, especially of high-potency cannabis, drives the earlier onset of psychosis in cannabis users. Schizophr Bull 40: 1509-17.

16. McHugh RK, Nielsen S, Weiss RD (2015) Prescription drug abuse: From epidemiology to public policy. J Subst Abuse Treat 48: 1-7.

17. Moeller FG, Barratt ES, Dougherty DM, Schmitz JM, Swann AC (2001) Psychiatric aspects of impulsivity. Am J Psychiatry 158: $1783-93$.

18. Jeronimus BF, Kotov R, Riese H, Ormel J (2016) Neuroticism's prospective association with mental disorders halves after adjustment for baseline symptoms and psychiatric history, but the adjusted association hardly decays with time: a meta-analysis on 59 longitudinal/prospective studies with 443313 participants. Psychol Med 46: 2883-2906. 
19. Bishara AJ, Pleskac TJ, Fridberg DJ, Yechiam E, Lucas J, et al. (2009) Similar Processes Despite Divergent Behavior in Two Commonly Used Measures of Risky Decision Making. J Behav Decis Mak 22: 435-54.

20. Chambers RA, Taylor JR, Potenza MN (2003) Developmental neurocircuitry of motivation in adolescence: A critical period of addiction vulnerability. Am J Psychiatry 160: 1041-52.

21. Nutt D, King LA, Saulsbury W, Blakemore C (2007) Development of a rational scale to assess the harm of drugs of potential misuse. Lancet 369: 1047-1053.

22. Huskinson SL, Naylor JE, Rowlett JK, Freeman KB (2014) Predicting abuse potential of stimulants and other dopaminergic drugs: Overview and recommendations. Neuropharmacology 87: 66-80.

23. Sulzer D, Sonders MS, Poulsen NW, Galli A (2005) Mechanisms of neurotransmitter release by amphetamines: A review. Prog Neurobiol 75: 406-33.

24. Greene SL, Kerr F, Braitberg G (2008) Review article: amphetamines and related drugs of abuse. Emerg Med Australas 20: 391-402.

25. Charles SB, Peter WA, Frank JD (2016) Drug of abuse. In: Pharmacology and Therapeutics for Dentistry 2: 584-602.

26. Wollner K, Stockhausen S, Mubhoff F, Madea B (2015) Death after intake of amphetamine/ecstasy: two case reports. Arch Kriminol 235 : 53-61.

27. Jones BE (2009) Glia, Adenosine, and Sleep. Neuron 61: 156-7.

28. Kamiya T, Saitoh O, Yoshioka K, Nakata H (2003) Oligomerization of adenosine A2A and dopamine D2 receptors in living cells. Biochem Biophys Res Commun 306: 544-49.

29. Solinas M, Ferré S, You ZB, Karcz-Kubicha M, Popoli P, et al. (2002) Caffeine induces dopamine and glutamate release in the shell of the nucleus accumbens. J Neurosci 22: 6321-4.

30. Arab L (2010) Epidemiologic evidence on coffee and cancer. Nutr Cancer $62: 271-83$.

31. Arendash GW, Cao C (2010) Caffeine and coffee as therapeutics against Alzheimer's disease. J Alzheimers Dis 20 Suppl 1: 117-26.

32. Santos C, Costa J, Santos J, Vaz-Carneiro A, Lunet N (2010) Caffeine intake and dementia: Systematic review and meta-analysis. J Alzheimers Dis 20 Suppl 1: $187-204$.

33. Ding M, Bhupathiraju SN, Satija A, van Dam RM, Hu FB (2014) Long-term coffee consumption and risk of cardiovascular disease: a systematic review and a dose-response meta-analysis of prospective cohort studies. Circulation 129: 643-59.

34. Carlsson S, Hammar N, Grill V, Kaprio J (2004) Coffee consumption and risk of type 2 diabetes in Finnish twins. Int J Epidemiol 33: 616-7.

35. Zhang Z, Hu G, Caballero B, Appel L, Chen L (2011) Habitual coffee consumption and risk of hypertension : a systematic review and meta-analysis of prospective observational studies. Am J Clin Nutr 93: 1212-9.

36. Middleton RM, Kirkpatrick MB (1993) Clinical use of cocaine: a review of the risks and benefits. Drug Saf 9: 212-7.

37. Kloner RA, Hale S, Alker K, Rezkalla S (1992) The effects of acute and chronic cocaine use on the heart. Circulation 85: 407-19.

38. Cressman AM, Natekar A, Kim E, Koren G, Bozzo P (2014) Cocaine abuse during pregnancy. J Obstet Gynaecol Can 36: 628-31.

39. Jones AW, Holmgren A (2014) Concentrations of cocaine and benzoylecgonine in femoral blood from cocaine-related deaths compared with venous blood from impaired drivers. J Anal Toxicol 38: 46-51.

40. Siegmund B, Leitner E, Pfannhauser W (1999) Determination of the Nicotine Content of Various Edible Nightshades (Solanaceae) and their Products and Estimation of the Associated Dietary Nicotine Intake. J Agric Food Chem 47: 3113-3120.

41. Moldoveanu SC, Scott WA, Lawson DM (2016) Nicotine analysis in several non-tobacco plant materials. Sciendo 27: 54-9.

42. Grana R, Benowitz N, Glantz SA (2014) E-cigarettes: A scientific review. Circulation 129: 1972-86.

43. Benowitz NL (2009) Pharmacology of Nicotine: Addiction, Smoking-Induced Disease, and Therapeutics. Annu Rev Pharmacol Toxicol 49: 57-71

44. Nutt DJ, King LA, Phillips LD, Independent Scientific Committee on Drugs (2010) Drug harms in the UK: a multicriteria decision analysis. Lancet 376: 155865 .

45. Alsalahi A, Alshawsh MA, Mohamed R, Alyousefi NA, Alshagga MA, et al. (2016) Conflicting reports on the role of the glycemic effect of Catha edulis (Khat): A systematic review and meta-analysis. J Ethnopharmacol 186: 30-43.

46. Murray CD, Le Roux CW, Emmanuel AV, Halket JM, Przyborowska AM, et al. (2008) The effect of Khat (Catha edulis)as an appetite suppressant is independent of Ghrelin and PYY secretion. Appetite 51: 747-50.

47. Numan N (2004) Exploration of adverse psychological symptoms in Yemeni Khat users by the symptoms checklist-90 (SCL-90). Addiction 99: 61-5.

48. Al-Abed AA, Sutan R, Al-Dubai SA, Aljunid SM (2014) Family context and Khat chewing among adult Yemeni women: A cross-sectional study. Biomed Res Int 1-6.

49. Al-Mugahed L (2008) Khat chewing in Yemen: turning over a new leaf. WHO-World Health Organization, Geneva, Switzerland. Bull World Health Organ 86: 741-2.

50. van Amsterdam J, Nutt D, van den Brink W (2013) Generic legislation of new psychoactive drugs. J Psychopharmacol, 27: 317-24.

51. Hájos N, Katona I, Naiem SS, Mackie K, Ledent C, et al (2000) Cannabinoids inhibit hippocampal GABAergic transmission and network oscillations. Eur J Neurosci 12: 3239-49.

52. Gatidou G, Kinyua J, van Nuijs AL, Gracia-Lor E, Castiglioni S (2016) Drugs of abuse and alcohol consumption among different groups of population on the Greek Island of Lesvos through sewage-based epidemiology. Sci Total Environ 563-564: 633-40.

53. Dasgupta A (2015) Chapter 1-Alcohol: Use, Abuse, and Issues with Blood Alcohol Level. In: Alcohol and its Biomarkers.

54. Measham F, Paylor I (2015) Alcohol Use and Abuse. In: International Encyclopedia of the Social \& Behavioral Sciences ( $2^{\text {nd }}$ Edn). Elsevier.

55. Coomber R, South N, (2004) In: Drug Use and Cultural Contexts 'Beyond the West': Tradition, Change and Post Colonialism. Free Association Books, London. 56. Gilmore I, Anderson W, Bauld L, Bellis M, Brown K, Drummond C, et al. (2013) Health First: An Evidence-based Alcohol Strategy for the UK. Published by the University of Stirling, Scotland, UK. A report published in association with the British Liver Trust and the Alcohol Health Alliance UK.

57. Haworth A, Simpson R (2004) Moonshine Markets: Issues in Unrecorded Alcohol Beverage Production and Consumption. Brunner-Routledge, New York.

58. Rehm J, Baliunas D, Borges G, Graham K, Irving H, et al. (2010) The relation between different dimensions of alcohol consumption and burden of disease: an overview. Addiction 105: 817-43. 
59. Pearson AL, Bowie C, Thornton LE (2014) Is access to alcohol associated with alcohol/substance abuse among people diagnosed with anxiety/mood disorder? Public Health 128: 968-76.

60. Babor T, Caetano R, Casswell S, G Edwards, et al. (2003) Alcohol: No Ordinary CommoditydResearch and Public Policy. Oxford University Press, Oxford.

61. Orford J, Velleman R, Natera G, Templeton L, Copello A (2013) Addiction in the family is a major but neglected contributor to the global burden of adult illhealth. Soc Sci Med 78: 70-7.

62. NICE Clinical Guidelines (2012) Opioids in Palliative Care: Safe and Effective Prescribing of Strong Opioids for Pain in Palliative Care of Adults. NICE Clinical Guidelines, Cardiff, UK

63. NIH-National Institute on Drug Abuse (2014) Prescription opioids and heroin. Res Report Series 1-8.

64. Holden JE, Jeong Y, Forrest JM (2005) The endogenous opioid system and clinical pain management. AACN Clin Issues 16: 291-301.

65. National Institute on Drug Abuse (2007) Research Report Series. Heroin: Abuse and Addiction. Drug Facts 1-3.

66. UNODC (2016) World drug report. United Nations publication.

67. Wang H, Naghavi M, Allen C, Barber RM, Carter A, et al. (2016) Global, regional, and national life expectancy, all-cause mortality, and cause-specific mortality for 249 causes of death, 1980-2015: a systematic analysis for the Global Burden of Disease Study 2015. Lancet 388: $1459-1544$.

68. Häkkinen M, Launiainen T, Vuori E, Ojanperä I (2012) Comparison of fatal poisonings by prescription opioids. Forensic Sci Int 10222: 327-31.

69. Bologini D, Ross RA (2015) Medical cannabis vs. synthetic cannabinoids: what does the future hold? Clin Pharmacol Ther 97: 568-70.

70. Bui QM, Simpson S, Nordstrom K (2015) Psychiatric and medical management of marijuana intoxication in the emergency department. West J Emerg Med 16: 414-17.

71. Ashton CH (2001) Pharmacology and effects of cannabis: a brief review. Br J Psychiatry 178: 101-6.

72. Hemachandra D, McKetin R, Cherbuin N, Anstey KJ (2016) Heavy cannabis users at elevated risk of stroke: evidence form a general population survey. Aust N Z J Public Health 40: 226-30.

73. Boeckx RL (1987) False positive EMIT DAU PCP assay as a result of an overdose dextromethorphan. Clin Chem 33: 974-75.

74. Johnson B, Streltzer J (2013) Risks associated with long term benzodiazepine use. Am Fam Physician 88: 225-6.

75. Nemeroff CB (2003) The role of GABA in the pathophysiology and treatment of anxiety disorders. Psychopharmacol Bull 37: 133-46.

76. Mursaleen LR, Stamford JA (2016) Drug abuse and Parkinson's diseases. Prog Neuropsychopharmacol Biol Psychiatry 64: 209-17.

77. Mayer EA, Knight R, Mazmanian SK, Cryan JF, Tillisch K (2016) Gut Microbes and the Brain: Paradigm Shift in Neuroscience. J Neurosci 34: 15490-6

78. Traub SJ, Levine MD (2017) Acute neurotoxicology of drugs of abuse. Handbook of Clinical Neurology (1 ${ }^{\text {st }}$ Edn). Elsevier 141: $485-505$.

79. Sacks S, Ries RK (2005) Substance Abuse Treatment For Persons With Co-Occurring Disorders: A Treatment Improvement Protocol (TIP 42), 263.

80. McHugh RK, Nielsen S, Weiss RD (2015) Prescription drug abuse: From epidemiology to public policy. J Subst Abuse Treat 48: 1-7.

81. Isbister GK, O’Regan L, Sibbritt D, Whyte IM (2004) Alprazolam is relatively more toxic than other benzodiazepines in overdose. Br J Clin Pharmacol 58: 88-95.

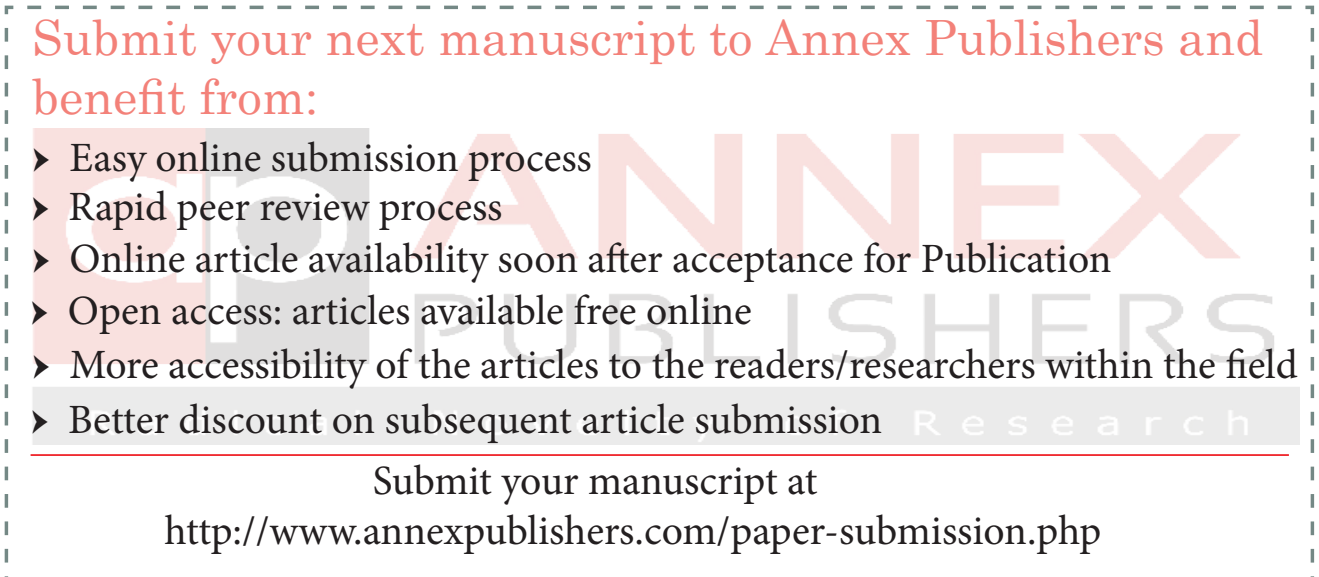

